\title{
Explorations of Universal Order and Beauty in Paul Hindemith's Symphony Die Harmonie der Welt
}

\author{
Siglind Bruhn
}

\begin{abstract}
A в Stract On 11 August 1957, the Munich Opera Festival premiered a recently completed opera by the celebrated German composer Paul Hindemith, Die Harmonie der Welt. Hindemith bases the dramaturgical and musical features of this opera on the scientific and spiritual content found in the writings of the 17th-century mathematician, astronomer and philosopher Johannes Kepler. Six years before he started working on this opera, the composer responded to a commission received from the Swiss conductor and patron of contemporary composers, Paul Sacher, by quickly composing and sending off the Symphony Die Harmonie der Welt which, as the composer writes in the program book for the first performance, "develops passages from the opera" in three movements entitled with terms taken from Boethius: I Musica instrumentalis, II Musica humana, and III Musica mundana. What are we to make of the explanation that the symphony "develops passages" from a work of which as yet nothing, neither libretto nor music, existed on paper? I want to show that it is tempting to assume a creative process that matures from the spiritual and aesthetic idea through a composition of musical material into components that would later serve both an instrumental and a music-dramatic representation of the subject.

KEYWORDS Paul Hindemith, Die Harmonie der Welt, Johannes Kepler, universal order, universal beauty
\end{abstract}

\section{I}

In the course of the disastrous years of the Second World War, when life was overshadowed by Nazi atrocities and trust in a harmonious future was as difficult as it was crucial for spiritual survival, the German composer Paul Hindemith (1895-1963) planned an opera about the life and thoughts of the mathematician, astronomer, and philosopher Johannes Kepler, an opera he was to call Die Harmonie der Welt, alluding with this title to Kepler's most famous treatise, Harmonices mundi. Throughout the war and the years immediately following it, which he spent in exile, teaching at Yale University, Hindemith kept mentioning the project in his letters; his notebooks show that he collected ample material about persons and issues he intended to portray. ${ }^{1}$ The dramatic story was to follow Kepler's mature life from his time in Prague, where he held the respected position as imperial mathematician at the court of Emperor Rudolf II but lost his wife and one of his three surviving children to the plague, through his troubled time at Linz where, after the emperor's death, he worked as "mathematician and cartographer," married his sec- 
ond wife, was accused by a Lutheran pastor of heresy because of his Calvinist understanding of the Eucharist, and wrote his magnum opus, to his descent into servitude and poverty as a man to calculate anything that needed calculating for the leading general in the Catholic emperor's army during the Thirty Years War, Count Wallenstein, and to his death upon learning that Wallenstein had fallen into disgrace and he, Kepler, was now without any income. This biographic frame was to serve as a background for the spiritual subject matter: a representation in words and music of Kepler's thinking about universal harmony. For many years though, Hindemith's academic duties as well as an ever more active international conducting career prevented him from writing anything down.

In 1951, the Swiss conductor and famous patron of contemporary composers, Paul Sacher, who knew about Hindemith's plan, suggested that he would celebrate the 25th anniversary of the Basel Chamber Orchestra with the world premiere of a "preview suite" of the future opera. Hindemith accepted the commission and speedily composed the Symphony Die Harmonie der Welt which, in the composer's words, "develops passages from the opera." The first performance took place on 25 January 1952 and was exceedingly well received; Wilhelm Furtwängler immediately adopted the symphony into his repertoire, declaring that he thought it Hindemith's best orchestral composition. Despite this encouragement, it took the composer another five years until he finally sat down to pen the libretto, which he completed on 1 September 1956. The music then followed swiftly; the full score carries the completion date 30 May 1957. The opera was premiered, under the composer's baton, during that year's Munich Opera Festival, on 11 August 1957.

What are we to make of the explanation that the symphony composed in 1951 "develops passages" from a work of which at the time nothing, neither libretto nor music, existed on paper? Two explanations are conceivable:

- that Hindemith - who was known to compose music much like Mozart, i.e., "in his head," and whose first draft often differed only insignificantly from the eventual fair copy - by 1951 already held the fully formed opera in his mind and merely "excerpted" from this virtual score;

- or that he had a very clear idea of the spiritual focus of the projected work and on this basis composed for Sacher three orchestral movements that could both work as a symphony and provide a quarry for passages to be used in his opera.

Both hypotheses are unusual but not without basis in view of Hindemith's 
working methods. In this essay, I will pursue the second hypothesis and assume a creative process that matured from the spiritual content of the intended opera through a composition of musical material organized into three symphonic movements to an eventual re-use of that material in various parts of the opera.

Hindemith had long been fascinated by Pythagorean thinking and its basis in music theory; he had found in the German mathematician, astronomer, and philosopher Johannes Kepler (1571-1630) a figure whose biography, scientific treatises, and writings about religious themes provided fertile ground from which to fashion an all-but-common operatic hero. Kepler's treatises, above all the Harmonices mundi, constitute a late pinnacle within the Pythagorean tradition. The laws he discovered mark a turning-point of scientific thinking that ushered in many of the developments on which astronomic theories of our time are still based. However, it is often overlooked that the major part of his opus magnum does not concern astronomy. Like every Pythagorean before him, Kepler regarded the law expressed in all aspects of nature as spiritual, accessible to the human senses only in the form of tonal relationships. His study is laid out in five books:

- In Book I, Geometry, he shows how the regular figures that manifest harmonic proportions are developed.

- In Book II, Architecture, he explains how the regular plane-geometrical figures can be joined to form solids.

- In Book III, Harmony, he demonstrates the relationship between the laws of music theory and proportional harmony in regular figures.

- In Book IV, Metaphysics, psychology, and astrology, he discusses the spiritual nature of harmonies and their manifestations in this world, above all the harmony created by the rays of the heavenly bodies shining upon the earth, and its impact on nature, the World-Soul, and the human soul.

- Finally in Book V, Astronomy and metaphysics, he draws on the laws of harmonic proportion to explain the range of each planet's orbital speeds along with the ratios of the fastest and slowest speed values of adjacent cosmic bodies.

As this overview shows, only Book V of Kepler's extensive treatise focuses on planetary motions and the famous three laws of planetary motions (which Hindemith has his operatic protagonist explain to his little daughter in a solemn hymn). 
As I have shown in much detail in a study entitled The Musical Order of the World: Kepler, Hesse, Hindemith, which traces the Pythagorean teaching on harmony to Kepler's theories, Hindemith's opera, and Hermann Hesse's Glass Bead Game, ${ }^{2}$ Hindemith bases the compositional features of his opera Die Harmonie der Welt - from the overall design through many intermediate levels of organization to a wealth of individual parameters - on the scientific and spiritual content of Kepler's writings. Let me mention here just a few of those aspects that have been unduly neglected in previous studies of the opera: the overture's cosmological message; Hindemith's mirroring, in the opera's overall design with its hidden but spiritually evocative analogies, of the structure and content of an original poem Kepler composed upon the death of two family members; Hindemith's translation of a piece of Keplerian juvenilia (the "Moon Dream") into dramatic action as well as musical form in the opera's central act; and the numerous explicit and indirect quotations of historic musical material as well as several instances of a play with symbolic numbers through which Hindemith probes Kepler's religious concerns.

The Pythagorean quest and its foundation in Greek music theory had considerable impact on Hindemith's thinking in the late 1930s. The most tangible proof can be found in the theoretical first volume of his treatise Unterweisung im Tonsatz, written in 1937. In the English translation, the introduction concludes with the following assertion:

[...] I am in agreement with views which were held long before the classic masters. We find such views in early antiquity, and far-sighted composers of the Middle Ages and of modern times hold firmly to them and pass them on. What did tonal materials mean to the ancients? Intervals spoke to them of the first days of the creation of the world: mysterious as Number, of the same stuff as the basic concepts of time and space, the very dimensions of the audible as of the visible world, building stones of the universe, which, in their minds, was constructed in the same proportions as the overtone series, so that measure, music, and the cosmos inseparably merged. ${ }^{3}$

It is in this spirit that I now turn to Hindemith's Symphony Die Harmonie der Welt - this supposed development from an as yet not physically extant opera.

\section{II}

The Symphony Die Harmonie der Welt consists of three movements. They are entitled with terms taken from Boethius: I Musica instrumentalis, II Musica humana, III Musica mundana. As you will recall, Boethius, 
writing in the early 6th century, transmitted the ancient knowledge about universal consonance to the Middle Ages. His writings on music and arithmetic, especially his five-volume Fundamentals of Music, provide a good overview of ancient music theory in its practical as well as speculative dimensions. In Book I:2 he explains music's threefold manifestation as musica mundana, musica humana, and musica instrumentalis - where musica mundana refers to music as an all-pervading force in the cosmos, musica humana to music as a principle unifying the human body and soul, and musica instrumentalis to music as sung and played by humans: concepts that reflect Pythagorean ideas. What the Basel concert audience probably understood as absolute music (since the opera to which one might trace the thematic material would not exist until five years later) was thus presented as indicative of the different ways in which humankind can experience universal consonance - and thus of the future opera's spiritual content rather than any of its specific dramatic scenes or characters.

The composer's brief introductory comment, published in the program book prepared for the Basel premiere, is useful particularly with regard to the general theme. It informs the concert audience that the prospected opera will portray Kepler "and his search for the harmony that undoubtedly governs the universe,"4 that the titles of the symphonic movements "refer to a classification often found in the ancients," and that the composer chose these terms so that they may "point to all those earlier attempts at recognizing universal harmony and understanding music as its sounding parable." With regard to specifics, Hindemith describes the music in the central movement as dealing with "matters of relevance for the dramatic characters' souls" and the final movement as "trying to symbolize the postulated harmony of the world in musical form." His description of the first movement as "containing music from operatic scenes in which adverse external circumstances hamper the protagonist's actions" is somewhat less satisfying - not least because this angle does not do justice to Boethius's concept of musica instrumentalis.

While a quick glance at the symphony may thus suggest that its movements juxtapose human experiences of disharmony in movement I, human experiences of imperfect harmony in movement II, and the perfect and blessed harmony that exists only beyond the human sphere in movement III, there is one crucial component that offsets this organization: the first of three components in movement I, which will eventually turn into - or: prove to have been intended as? - the oper- 
atic overture. I would like to point to a few basic musical features in order to show how this opening segment is a preview of the Pythagorean (and Keplerian) topic as a whole, rather than of one of Boethius's three aspects of harmony.

The passage comprises 33 measures; these are firmly rooted in the pitch E. Throughout the first 25 measures, E sounds as a pedal in the timpani; in mm.1-9 it is additionally reinforced by violins and violas. Moreover, Hindemith has the strings approach each $\mathrm{E}$ in ascending scalar runs E-F-G-A-B-C-D-E. With their framing octave, the runs confirm E as the tonal center; furthermore, the pitches establish a mode that, in the Pythagorean thinking to which the work's title alludes, was considered the fundamental scale. The way in which Hindemith begins his work can thus be interpreted as a deliberate hint at the overarching subject matter. $^{5}$

In measure 2, the trumpet introduces the overture's one and only motif. It consists of a mordent on E followed by a descent through six fourths. This descent is broken by an octave reallocation at the point of enharmonic change. It links the tonic E to its polar opposite, the tritone $\mathrm{B} b$. The plunge is complemented by a slow scalar ascent launched from the note $F$, the next step in the circle of fifths after $B b$.

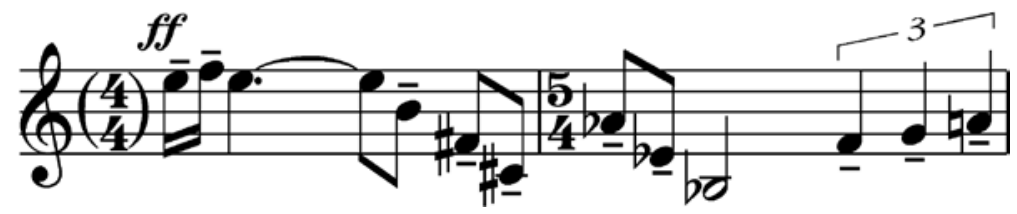

Figure 1: Hindemith, Symphony Die Harmonie der Welt, movement I, first segment, central motif.

The pitches of this motif are symbolic in two ways. The mordent E-F-E employs the tones that, in Kepler's famous calculations, correspond to the two pitches of the earth's orbit, MI and FA. As Kepler interprets this in a marginal gloss toward the end of chapter 6 in Book V of Harmonices mundi, "The Earth sings MI FA MI, so that even from the syllables you may guess that in this home of ours, MIsery and FAmine hold sway." ${ }^{\circ}$

The remainder of the motif then travels clockwise through the circle of fifths, skipping only twice, at the very end, over intermediate tones: 


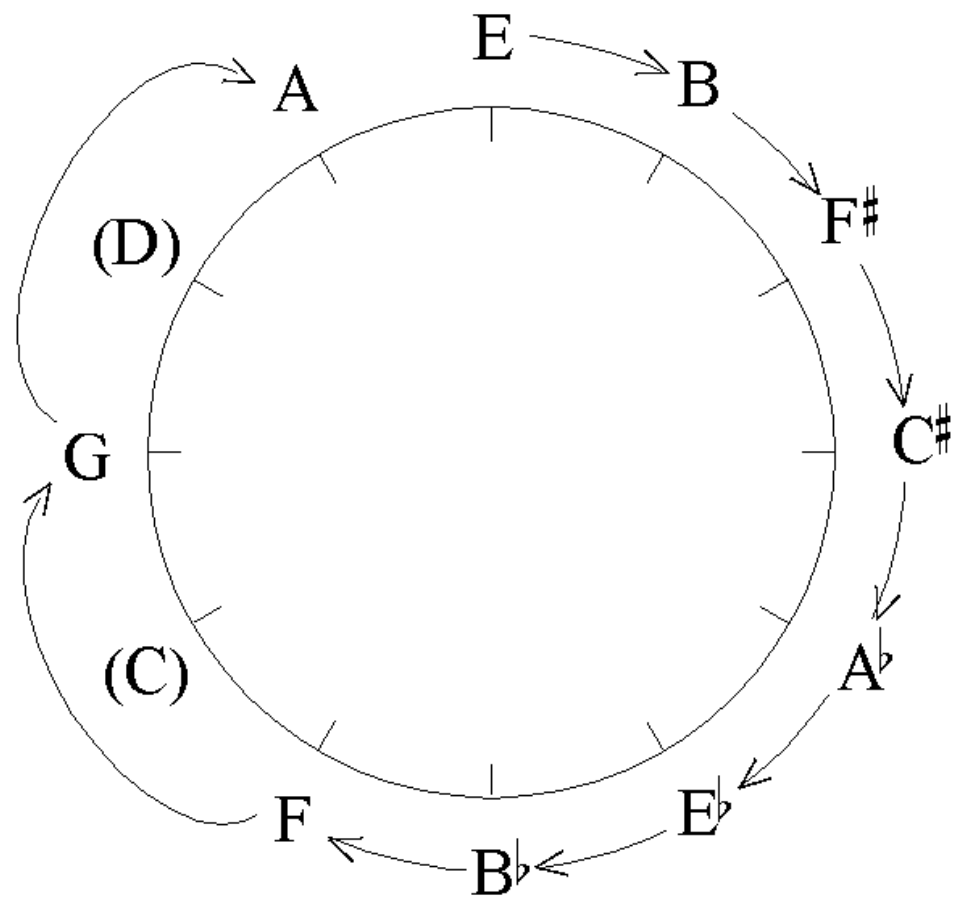

Figure 2: The basis of the central motif in the circle of fifths.

This opening passage about universal harmony as such is followed by two segments that can be taken to justify the title musica instrumentalis. One is a march, i.e., a genre that might be considered as one of the cruder musical representations of, or accompaniments to, bodily motion. In the eventual opera, Hindemith will use this passage for a scene at the beginning of act II, in which a cynical university dropout and political agent operates without any sympathy or consideration on behalf of his employer, Count Wallenstein, as he chases slum dwellers from the site on which the prosperous general intends to have a grandiose palace built. The movement's third component, too, constitutes unpretentious music; it will eventually provide the refrain and first episode in a rondo. Within the trial scene of act III, centering on Kepler's mother and her eccentric behavior, this music underlies the magistrate's reading of the hilarious accusations of witchery.

What seems striking in all this is that Hindemith, when he sat down to compose the actual opera, used all three segments of these first symphonic movements for dramaturgic instances in which Kepler is conspicuously absent, both on stage and with regard to the direct symbolic significance 
of the musical material. If the composer of the symphonic commission for Sacher still believed that what he subsumed under the heading musica instrumentalis would eventually serve as music for "adverse external circumstances that hamper the protagonist's actions," he reconsidered later. Ultimately, the music in the two dramatically realized components of the symphony's first movement points to situations of desperation experienced by the most vulnerable among Kepler's contemporaries: those who are too poor to have proper homes, and those whose thoughts and beliefs differ enough from the majority as to threaten their good standing within society and jeopardize their protection from willful incrimination. But then again: In the course of his life, the historical Kepler himself experienced unemployment and with it, the threat of poverty; as a Lutheran who believed that during the Eucharist, Christ was present in spirit, the historical Kepler also experienced punishment for deviant thinking; all of these themes represent concerns alluded to in the opera. In this larger and indirectly symbolic sense, the music of the musica instrumentalis movement does indeed refer to paradigmatic instances in which the protagonist's search for harmony is adversely affected.

\section{III}

The music heard in the second movement will years later turn into the spiritually central scene of the opera's second act. 58 measures in very slow tempo prefigure the scene in which Kepler, speaking to Susanna, the young women who will become his second wife, expresses his gratitude for her confidence. The first segment is dominated by an intense cantilena, hovering over a homophonic string accompaniment in dotted rhythms that are scattered over measures alternating irregularly between 4/4- and 3/4 time. The cantilena's memorable head motif is first presented in unison by four woodwinds. In the opera's second act, Hindemith will add a vocal line in which Kepler articulates his faith in

new research into the most profound order and magic of the laws as manifested in music, geometry, in the structure of plant and animal, the course of the stars, in essence, motion, relation, in all that has been created. Which also includes the place, thought, deed, and destiny of human beings; from which one should learn to deduce the divine Fiat, the magic Word - spoken at the beginning by the Creator - that brought forth the world and preserves it in Light. Should I not exhort the thinkers, artists, rulers of this earth to accommodate themselves within the confines of their work to that Word, so that through them, humankind will become conscious of the harmony of the world? 


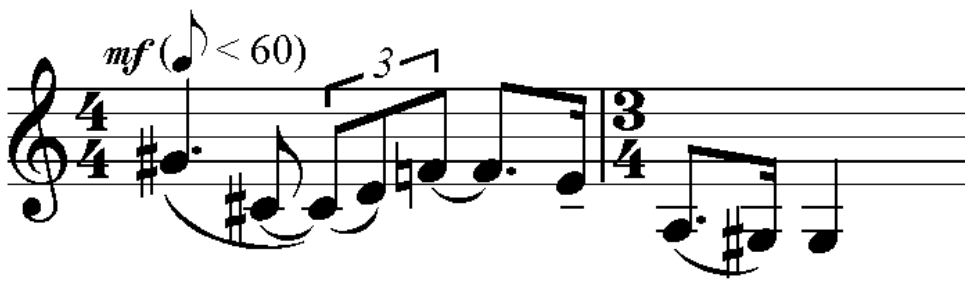

Figure 3: Second symphonic movement and second operatic act: Kepler's creed motif.

The subsequent segment retains the slow tempo, the melodic predominance of woodwinds over scattered homophonic utterances in the strings, and the irregular alternation of measures in $4 / 4$ and $3 / 4$ time. The initiating motif and the cantilena it spawns, while different in its details, emerge as a reply of sorts to the melodic incorporation of Kepler's creed. Its main difference is its polyphonic pairing - and interacting - with a line presented in the oboe. Fitting for a musical emblem that combines the "response" in the horizontal dimension with the interrelationship on the vertical plane, Hindemith will later allocate the leading voice to Susanna, allowing her to begin with a creed of her own. Hindemith has Kepler end his "creed," as I have shown, by expressing his responsibility toward the Truth with the words "Should I not exhort the thinkers, artists, rulers of this earth to accommodate themselves within the confines of their work to that Word, so that through them, mankind will become conscious of the harmony of the world?" The young woman balances Kepler's professional ethics with her idea of universal harmony, couched in an ethics of care: "Should not we ourselves also manage, within the signs of such soundings and with the best that resides in us to be close to our neighbors, understand them, better any evil, forgive, destroy hostility, propagate love?"

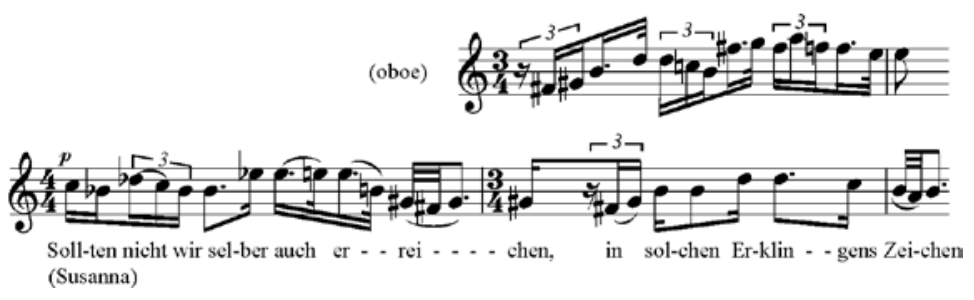

Figure 4: Susanna's interpretation of harmony as thoughtful interrelatedness. 
The musical motif expressing this aspect of "harmony in the world" is contrapuntal: i.e., it consists of two melodic lines which move with a great deal of independence (as would two individuals) but in constant regard to uphold the harmony with one another. This is the kind of musical symbolism that some listeners at the Basel concert might already have discerned in the second movement of the symphony; the operatic scene in which the motif and its development reappear only serves to confirm this aspect.

There follows in the symphonic movement a third segment in the style of a wistful dance in languishing $3 / 4$-time. The solo violin plays a very soft, high-register echo of Kepler's creed cantilena, accompanied by soloistically playing strings and rhythmicizing percussion - timpani, glockenspiel, small cymbal, and triangle.

What message about Kepler and his quest for universal harmony might this music have suggested to the symphony audience? (Perhaps: The universe moves in a way that creates harmony according to the loftiest notions; it is organized in complicated superimposed rhythms that chime in various tone colors?) For the opera, Hindemith will superimpose a vocal line in which the young bride articulates a stunning (and maybe even a little ironic?) outlook on her marriage to the century's greatest explorer of universal harmony:

I stepped into an Eden of numbers, calculations, proportions, where formulas live instead of snakes, apples are harmless spheres. No flaming sword will drive us out; I will be happy to stay with Adam in his wisdom and stillness. Blessed am I, blessed am I.

\section{IV}

The symphony's third movement, the musical representation of musica mundana or cosmic harmony, will make its way most directly into the eventual opera: it underlies the second half of act V. Hindemith later merely added vocal lines to the orchestral texture and interpolated a few recitativic inserts. Dramaturgically, Hindemith the librettist comes as close as is scenically defensible to an operatic presentation of cosmic harmony. The music underlies a celestial apotheosis: following Kepler's death, the opera's eight primary dramatis personae appear as eight luminous allegories, gathering in the starry sky for an ecstatic praise of true harmony.

For this ultimate manifestation of supreme harmony, Hindemith composes two pairs of polyphonic segments, both based on fugues and 
passacaglias. The distinction between the two forms need not concern us here. Briefly: in a fugue, a musical subject travels through all or most of the participating voices, through different keys, and often assumes different shapes; in a passacaglia, the musical subject stays in the same key and shape throughout. What matters for our symbolic interpretation is that both musical forms are complex structures in which all participants follow their individual course while always remaining in consonance with all others, and that each segment of the structures is based on the same idea - what we call a subject. So here, Hindemith composes a fugue, a passacaglia, a hybrid, and a second passacaglia - each form based on a single entity that organizes the whole. The pairs are separated by a cadenza initiated by the flute and answered by the bassoon.

On all levels of this movement, Hindemith engages in numerical play based on combinations of the numbers 5 and 9. Immediately obvious is the design of the cosmic transfiguration in 5 segments (fugue, passacaglia 1, cadenza, hybrid, and passacaglia 2); I will later point out other instances of five-ness. Hindemith refers here in his structural symbolism to the fact that, like people in many other ancient civilizations, the Pythagoreans perceived the number 5 as endowed with magical power. We may all have heard that five-pointed figures are seen as set apart from other items of plane geometry. They are considered mystical in most traditions. The pentagram particularly was also deemed magical: it is the simplest star shape that can be drawn with a single line (for this reason it is sometimes called the Endless Knot) and with no other reference than the angles on the pentagon's circumference. Pentagrams have been found on potsherds at Ur dated to ca. 3500 B.C.E. In later periods of Mesopotamian art, pentagrams appear in royal inscriptions, symbolizing imperial power. The Hebrews associated the number 5 and the symbols based on it with Truth and the five books of the Pentateuch; the Christians later linked them to the five wounds of Christ; the Muslims know five pillars of faith and five daily times of prayer. In a similar spirit, the Pythagoreans regarded the pentagram as an emblem of perfection; Kepler takes this up, and so, in his music on Kepler's ideas, does Hindemith. Toward the end of my presentation, I will point to Hindemith's ultimate (and superior) use of five-ness in his musical representation of universal harmony.

Meanwhile, the number of subject entries in the four polyphonic forms plays with the figures 9 and 3 . As you will recall, the figure 9 is not one of the common numerical symbols in the tradition of Western art; this opens it up for new associations. It can be understood as related 
to 3 - be it that the larger number appears as the power of the smaller $(3 \times 3=9)$, be it that the two add up to the numerical emblem of completion $(3+9=12)$. In Pythagorean music theory, 9 denotes the perfect tone the only candidate among the three whole-tone intervals resulting from the series of partials that is considered fully "in tune." In his symphonic movement (and in the eventual operatic component of cosmic transfiguration), Hindemith seems to play with all these associations, emphasizing them in repeated couplings of 9 with 3 and depicting their precarious stability by means of conspicuous deviations.

All four polyphonic structures are motivically interrelated. Here are the first two:

Subject of the fugue:
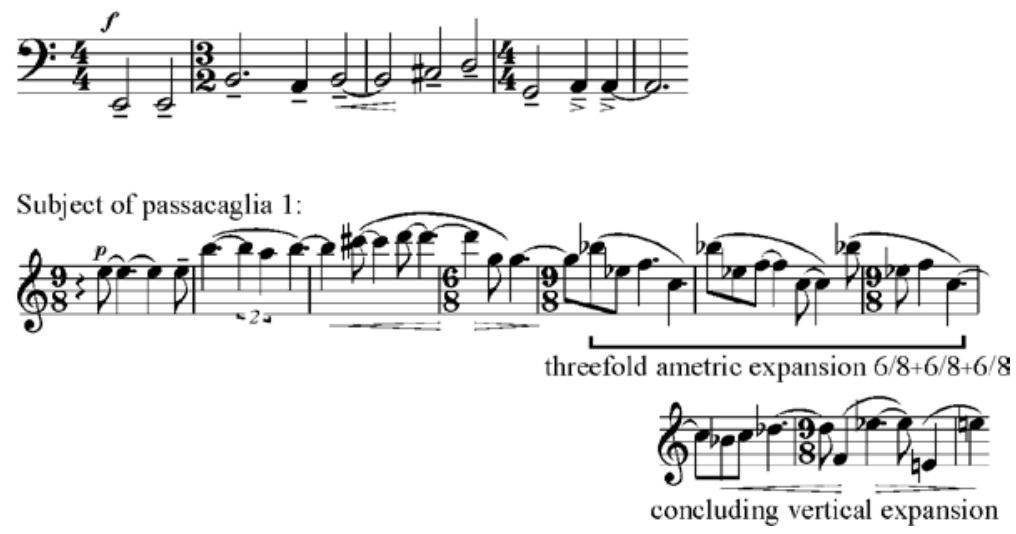

Figure 5: The subjects of the cosmic fugue and first passacaglia.

The fugue consists of nine subject entries; these travel through various keys but begin, center, and end on the pitch E. The subject of the first passacaglia presents a rhythmically complex and much extended variant of the same melodic contour while remaining securely moored on the Pythagorean thinkers' central tone E. In the fugue launching the symphony's third movement, the subject manifests in nine entries, three of which are strettos (i.e., group entries in stacked, substantially overlapping imitation). In the course of the first passacaglia, the thematic phrase is heard ten times. Several indications in the music call the listeners' attention to the fact that something is curious here, that an odd "extra" entry disturbs an underlying regular total of nine. The nine regular entries, carried out by varying instruments, describe a gradual crescendo from $p$ to ff. Quite early in the process, this measured build-up is upset when a trumpet-led statement suddenly bursts 
out. In the symphony, the loudness is still subdued; in the eventual opera, the extra statement underscores a dramatic occurrence that provides a possible explanation for its emergence. The trumpet-led subject entry does not sound in connection with interactions between the cosmic allegories. Instead, it resonates into the heavenly serenity from violence-ridden earth, where four officers prepare to murder General Wallenstein shortly after Kepler's death. By the time this crime is committed, the cosmic impersonations have long turned away from the erroneous ways of the human world. Just as this murder interrupts the incipient celestial calm, so the redundant tenth subject entry disturbs the passacaglia subject's perfect number of nine statements with their gradual increase of intensity.

Thematic shapes very similar to the two related contours shown above for the movement's fugue and first passacaglia underlie the hybrid form and the second passacaglia. In the former, the thematic "head" is rhythmically much simplified; in the latter, it returns to the original rhythm. The relatively short polyphonic hybrid is limited to three subject entries, of which two are single-voiced while the third is imitated in overlap. The second passacaglia features nine entries, bringing the total number of related subject entries in this segment of the movement to the figure of completion, 12.
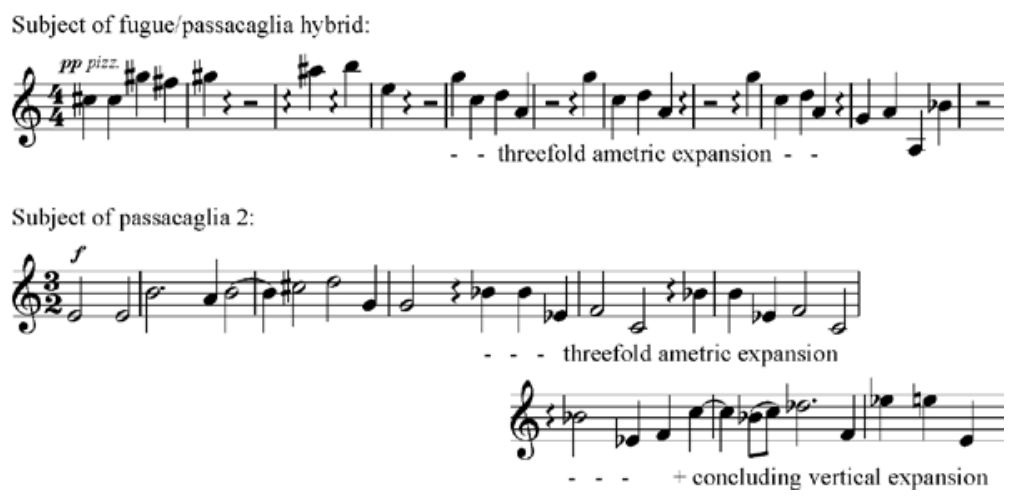

Figure 6: The subjects of the hybrid form and of the second passacaglia in the cosmic fugue. 


\section{V}

In the eventual opera, Hindemith derives the four polyphonic forms I have just shown you from a fifth one. This earlier "source" statement of cosmic harmony, as it were, emerges in an unexpected place and function: it forms the central episode in the "moon rondo," one of Hindemith's two musical translations of Kepler's early "Moon Dream” fiction. The background to this scene is worth telling, since it marks what might be considered the anticlimax of the pursuit of harmony and aesthetics within the composition (and in its historical protagonist's life, one might add.) Act III of Hindemith's opera is entirely based on a part of Kepler's creative imagination that combines the scientist's passion for astronomy, a portrait of Kepler's cranky mother, and the composer's interest in ideal figures and bodies.

Abandoned by a husband who sought the adventures of a mercenary life, the historical mother Kepler was harsh and haughty. She survived thanks to a special gift: her intimate knowledge of the medicinal effects of plants and herbs, handed down through generations of wise women in her family. But her abrasive behavior provoked her neighbors, who eventually used her uncanny healing abilities as an excuse for getting at her by denouncing her as a witch. After years of written charges and defenses (the latter from her son Johannes's pen), she was arrested in 1620 and, had it not been for the dispense Kepler obtained from the High Court, would almost certainly have been executed.

Beyond filial loyalty, Kepler had strong reasons to do everything in his power to help his mother, since he may have involuntarily contributed to her plight. As a student in Tübingen, Kepler had written a fictional story about a voyage to the moon. ${ }^{8}$ Drawing on his fascination with astronomy and meteorology, his extraordinary talent for spatial imagination, and a fertile poetic mind, Kepler's Somnium describes in great detail not only the moon's geography and climate, but also the living conditions of moon dwellers as well as the appearance of the starry sky from their perspective. This essay - which Kepler, following a long tradition, couched as a dream - has been called a path-breaking predecessor of science fiction. ${ }^{9}$ Although it was printed only posthumously, it is assumed to have circulated from about 1608 onward in several handwritten copies.

In a later revision, Kepler framed the "travelogue" with a story about an Icelandic folk herbalist and her son, an aspiring scholar who leaves home to train as an astronomer. Returning from his studies, the young scientist urges his mother to reveal the source of her unusual knowledge, and learns that she has long been receiving instructions from a demon. 
It is this demon, now purposefully conjured by mother and son together, who then describes the voyage to the moon that was the initial cell of Kepler's imaginative text. Only much later did Kepler understand what conclusions this tale could invite in the heyday of witch trials, especially since he had portrayed the fictitious astronomer's mother and alleged witch with the cranky character and demeanor everybody resented in his mother.

In act III of Die Harmonie der Welt, Hindemith combines two scenes that must be read as creative extrapolations of the two components comprised in Kepler's “Moon Dream" essay: the interest in the moon, along with that in the change of perspective a voyage to it would entail, and the relationship between a cranky folk herbalist (who may or may not be a witch) and her astronomer son. Both scenes are composed as rondos. If we continue to read musical forms symbolically, it is easy to see how in both cases, various peoples' thoughts turn round and round, circling in the first case, the moon as a heavenly body, and in the second, all that might be related to lunacy and intercourse with demonic forces.

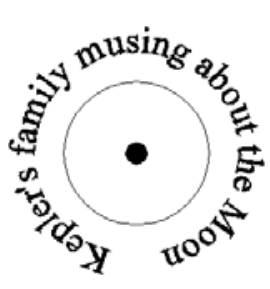

Act III, sc. 1: "moon rondo"

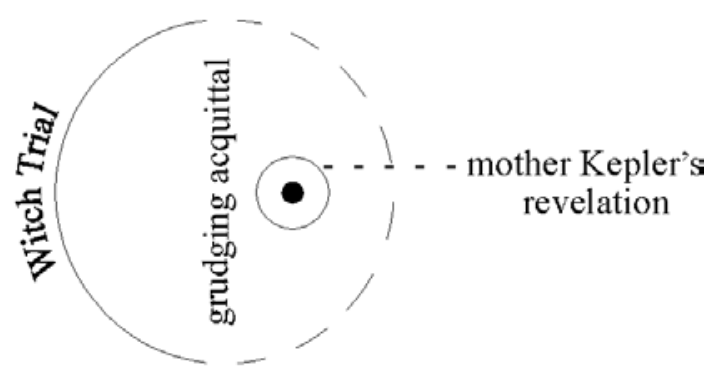

Act III, sc. 2:

"witch trial rondo"

Figure 7: The context for the "source" of the four views of cosmic harmony.

Interestingly, each scene shows one musically stunning deviation from the traditional rondo form. I will concentrate on the first, as it contains the "source" of the cosmic allegories' views of universal harmony.

So what is the manifold significance of the moon, explored in the first rondo? For naive souls like Kepler's little daughter, the moon is humankind's affectionate if unknowable friend, inhabited by "the little man in the moon" whose solitude is to be pitied; for superstitious people like mother Kepler, the moon is an accomplice and facilitator of all manner of dubious acts; for conscientious people like Kepler's wife Susanna, moonlight defines a time of reflection and self-questioning set apart from the 
busy sunlit hours of everyday life; for a scientist like Kepler, the moon is an object of investigation, perhaps a means toward a growing understanding of the eternal laws of the cosmos. A surprising fifth dimension is added by the chorus of "voices from the moon," who describe the moon's primary quality as being only and fully herself. They assert the moon's intrinsic lack of emotions (whether compassionate or vengeful) and debunk all myths humans have invented regarding alleged lunar interventions in human endeavors and fates. The many sides from which the moon is seen here function as an antidote of sorts to the superstitions that dominate the subsequent trial scene.

The moon rondo is held together by a refrain that juxtaposes a pastiche children's song addressed to the "little man in the moon" with choral statements by the lunar voices about the "world without clemency, airless, cloudless, rainless."

The episode in the moon rondo that contains the "source" of the representation of universal harmony is highly unusual in terms of its emotional impetus, its structural features, and its verbal content: in gesture and dramaturgical attitude, this is a hymn. Sung by the earnest scientist Kepler who at this moment is surrounded by three generations of women with very divergent but mainly metaphorical interpretations of the moon, this hymn is most bizarre. Rondos, as you are probably aware, originated as rustic dances. Their refrains are typically simple enough in melody, rhythm, and structure to be memorable for the crowd of untrained dancers asked to skip around a circle. Episodes, inserting show dances by featured couples, may be more ambitious in all respects but are still to be danced. A hymn inserted into a rondo is about as fitting as would be a religious sermon preached at the height of a cheerful garden party.

Kepler's hymn is based on a recurring thematic phrase which those of you who read music will recognize. Its twelve statements - six each in two analogous halves - all sound in the lowest register beneath a largely homophonic texture, as is typical in a passacaglia. At the same time, and atypical of a passacaglia, the statements wander through different keys as would the subject entries in a fugue, and are each challenged by a genuine counterpoint, another characteristic feature of fugues. (So this is another hybrid of fugue and passacaglia.) The meter in the thematic phrase alternates regularly between $2 / 2$ and $3 / 2$ time, as though Hindemith wanted to remind listeners both of the magic number five and of the fact that it was Kepler's search for simple proportions that inspired his insights. In the hymn's first half, Kepler, pretending to answer his little daughter 
who is worried about what happens to the mountains on the moon when it waxes and wanes, stresses the importance of "the formula."

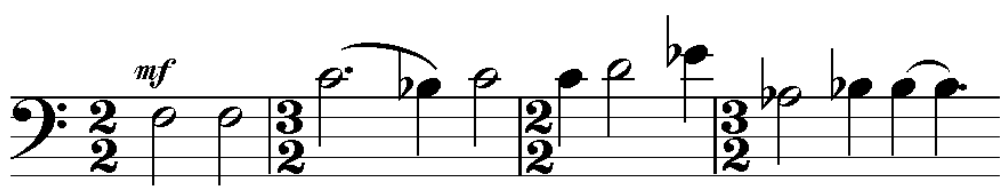

Wo nichts Greif - - ba - res, wo die For-mel wohnt

Figure 8: The subject of the hymn that serves as an episode in the moon rondo.

Immediately afterwards, Hindemith has him add succinct definitions of his second and third planetary laws ("where equal areas fit into the elliptical orbits in equally long times" and "where the third great law governs: the revolution of two celestial bodies in squared and cubed proportion revealed through God's wisdom"). ${ }^{10}$ All the while, the hymn tune sounds in various bass instruments.

\section{Coda}

As a comparison of this contour with the four subjects discussed above shows, they are all intimately related. In musical terminology: the four latter forms are developed from the earlier one.

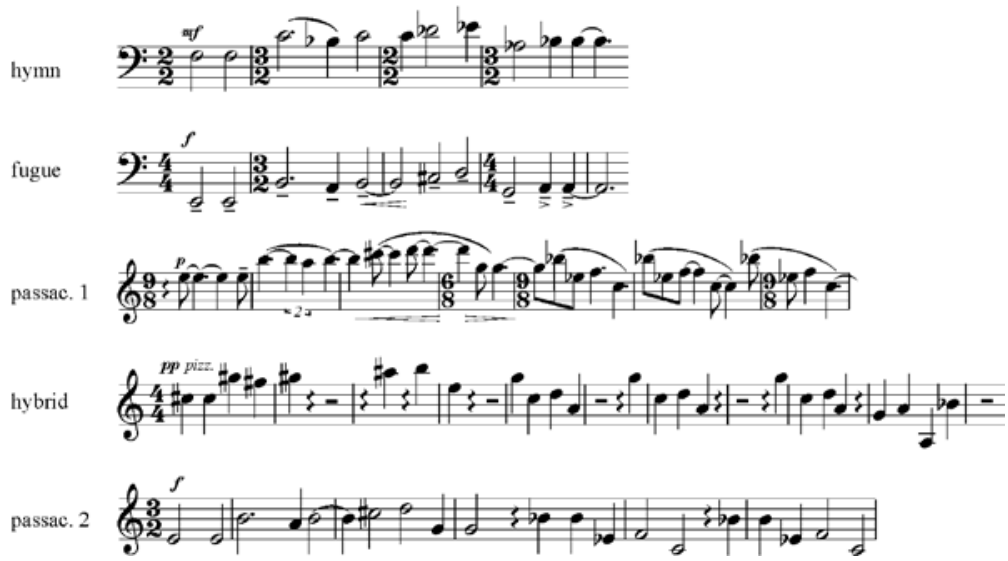

Figure 9: Five musical subjects speaking of cosmic harmony.

This makes sense in the opera. In the symphony, however, it brings us full circle to my initial question. Since none of the music that will 
eventually be heard in act III forms part of the symphony, the idealistic "source" of the four cosmic subjects will officially materialize only five years after the symphony was premiered.

It befits Hindemith's tongue-in-cheek translation of astronomic into musical relationships that the ultimately five polyphonic forms, developed from the same thematic substance, are conceived in perfect consonance also with regard to a dimension that no human sense can consciously ascertain. The ideal durations of the five segments, calculated according to the composer's tempo indications, are "in harmony" in just that sense: they relate to one another in the simple ratios that correspond to musical consonances:

hymn : fugue : passacaglia $:$ hybrid $:$ passacaglia $=5: 8: 9: 3: 9$.

If Kepler could claim to "hear" the relative angular speeds of planetary orbits as intervals, surely we are permitted similarly to claim that we "hear" the harmony in the relative durations of the corresponding musical segments. With reference to the fundamental E of Pythagorean musical philosophy as well as Hindemith's symphony and opera on the life and thinking of Johannes Kepler, the praise of cosmic order in Die Harmonie der Welt then sounds in this aesthetically pleasing, simple and harmonic contour.

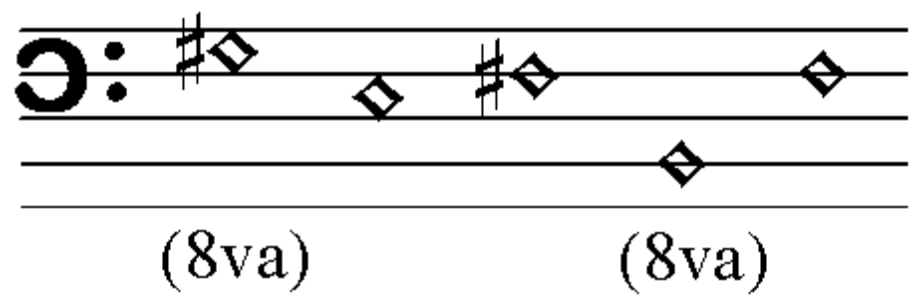

Figure 10: "Consonance" in the extension of the five passages built on the subjects of cosmic harmony.

\section{Notes}

1. I owe thanks to the Hindemith Institute in Frankfurt for the opportunity to study the composer's ample notes, which chronicle his reading and preparatory thoughts on the opera. These notes reveal the impressive breadth of his historiographic research as well as his great interest in understanding Kepler's scientific and religious concerns. One of three notebooks entirely reserved for research toward this opera contains in its seven sections biographical sketches of 


\section{Siglind Bruhn}

members of Kepler's family, portraits of other persons of significance in Kepler's life, drafts for various scenes and text passages, notes on living conditions, frequency of disease and death, scientific discussions, religious controversies, and political developments of the time, memos documenting Hindemith's studies of issues important for Kepler's professional life, as well as a reading list of more than 60 titles.

2. Siglind Bruhn, The Musical Order of the World: Kepler, Hesse, Hindemith. (Hillsdale, NY: Pendragon Press, 2005).

3. Paul Hindemith, The Craft of Musical Composition, Vol. I, Theory. Trans. Arthur Mendel (New York: Associated Music Publishers, 1945), pp.12-13.

4.Programmheft zur Uraufführung (Munich: Prinzregententheater, 1957), pp. 37-38.

5. Admittedly, Hindemith does not quote the scale on which ancient Greece based its music theory in its neutral form, i.e., descending, slow, and serene. The fervent upward burst that he fashions instead owes itself to a sense for dramatic effect.

6. Kepler, The Harmony of the World, translated into English with an introduction and notes by E. J. Aiton, A. M. Duncan, J.V. Field (Philadelphia, PA: American Philosophical Society, c1997), p.440. The original Latin reads: "Tellus canit MI FA MI ut vel ex syllaba conjicias, in hoc nostro domicilio MIseriam et FAmen obtinere." Kepler, writing in Latin, uses the fixed DO still common today in Romance-language speaking countries, not the movable DO of solmization.

7. Paul Hindemith, Die Harmonie der Welt: Textbuch (Mainz: B. Schott's Söhne, 1957), p. 35, and score, Act II, cue [15].

8. It was eventually published under the title Somnium seu opus posthumum de astronomia Lunari. For an English translation see Edward Rosen, Kepler's "Somnium": The Dream, or Posthumous Work on Lunar Astronomy (Madison, WI: University of Wisconsin Press, 1967).

9. Mechthild Lemcke, Johannes Kepler (Reinbeck bei Hamburg: Rowohlt, 1995), p. 96.

10. I find the composer's poetic translation of these all-but-simple astronomic definitions quite admirable. Here is one of the possible English translations of the three planetary laws and, juxtaposed with each of them, the adaptation for the operatic stage:

(1) The historical Kepler: "The orbit of every planet is an ellipse with the sun at a focus." / Hindemith's Kepler: "Was ich als Regel erfuhr alles Schwingens in himmlischen Weiten: der Sternläufe elliptische Natur."

(2) The historical Kepler: "A line joining a planet and the sun sweeps out equal areas during equal intervals of time." / Hindemith's Kepler: "Wo den elliptischen Bahnzügen in gleichlangen Zeiten gleich große Flächen sich einfügen.” 
(3) The historical Kepler: "The square of the orbital period of a planet is directly proportional to the cube of the semi-major axis of its orbit." / Hindemith's Kepler: "Zweier Himmelskörper Revolution in die Quadrat- und Kubusproportion durch Gottes Weisheit gebracht." 